\title{
Flume experiments on vegetated alternate bars
}

\author{
Giulio Calvani ${ }^{1, *}$, Simona Francalanci ${ }^{1}$, and Luca Solari ${ }^{1}$ \\ ${ }^{1}$ Department of Civil and Environmental Engineering, University of Florence, Florence, Italy
}

\begin{abstract}
The planform morphology of a river reach is the result of the combined actions of sediment motion (erosion, transport and deposition), hydrological regime, development and growth of vegetation. However, the interactions among these processes are still poorly understood and rarely investigated in laboratory flume experiments. In these experiments and also in numerical modelling, vegetation is usually represented by rigid cylinders, although it is widely recognized that this schematization cannot reproduce the effects of root stabilization and binding on riverbed sediment. In this work, we focus on the effects of added vegetation on morphological dynamics of alternate bars in a straight channel by means of flume experiments. We performed laboratory experiments reproducing hydraulic conditions that are typical of gravel bed rivers, in terms of water depth, bed slope and bed load; these conditions led to the formation of freely migrating alternate bars. We then employed rigid vegetation that was deployed on the reproduced alternate bars according to field observations. Various vegetation scenarios, in terms of density and spatial arrangement, were deployed in the flume experiments such to mimic different maintenance strategies. Results show the effects of rigid vegetation on the alternate bar configuration on the overall topographic pattern, the main alternate bar characteristics (such as amplitude and wavelength) and migration rate.
\end{abstract}

\section{Introduction}

Nowadays, the whole scientific community agrees on the idea that spatial and temporal evolution of a river reach is governed by the mutual interactions among flow discharges, sediment transport processes (erosion, motion and deposition) and presence, growth and decay of riparian vegetation. The combined actions of these three factors act at different spatial scales, ranging from the size of the single plant to the length of the river reach $\left(\sim 10^{-3}\right.$ $-10^{4} \mathrm{~m}$ ) and involving processes and alterations which develop and evolve in considerably different time scales ( $\sim 1 \mathrm{~s}-10$ years). The study of the mechanisms at the foundations of these interactions is the key point to understand, model and rightly predict the morphological evolution of a fluvial environment [1].

In the literature, some models to explain spatial and temporal evolution of vegetated river were proposed; the first attempt to take into account the presence of riparian vegetation was made by Murray and Paola in 2003 [2], by investigating the effects of sediment stabilization due to the roots on morphological pattern alteration. Subsequent

\footnotetext{
*Corresponding author: giulio.calvani@unifi.it
} 
models have further incremented the goodness in predicting morphodynamic evolution thanks to physics-based equations [3-6]. However, they have still involved the simplifying hypothesis of vegetation as uniformly distributed rigid cylinders [7], which substantially limits the applicability of such models to real cases, particularly when flexible juvenile plants are present[8].

Thus, while it is of fundamental importance to sustain numerical model results with laboratory investigations, scientific literature is quite scarce. Only in the last decades, river morphodynamics has been investigated by means of flume experiments also including the biological component given by riparian vegetation by using either rigid cylinders [7, 9, among others] or real vegetation $[10,11]$. However, results of such flume experiments reflect the unscaled effects of plants.

In this work, we investigate the interactions between rigid riparian vegetation and freely migrating alternate bars in a straight channel. Particularly, the specific objectives concern the understanding of alterations induced by the presence of vegetation on the overall topographic pattern (and in particular on wavelength and amplitude) and migration rate of alternate bars..

\section{Materials and methods}

We have carried out the experiments in the Laboratory of fluvial hydraulics and biofluid dynamics at the School of Engineering of the University of Florence, in a $10.5 \mathrm{~m}$ long and $0.43 \mathrm{~m}$ wide flume. To ease the displacement of vegetation, flume was previously covered with $8 \mathrm{~cm}$ thick phenolic foam on top of which a mobile bed layer of poorly graded sediment $\left(\mathrm{D}_{50}=1.25 \mathrm{~mm}, \mathrm{C}_{\mathrm{u}}<6\right)$ was arranged. Grain size was chosen such to avoid formation of small bedforms, such as ripples and dunes. The same sediment has been used to feed the channel during the running of each experiments.

The conditions for the formation of alternate bars in straight channel (i.e., flow discharge, $Q$, and bed slope, $s$ ) were defined according to the linear theory of Colombini et al. [12] and considering the Wong and Parker formula [13] for the sediment transport rate, which we found suitable for our experimental conditions. Differently from previous flume studies on bars, we did not reduce the inlet channel width (e.g., by using a transversal plate). In such a way, we allowed alternate bars to freely develop and migrate downstream. Various combinations of flow discharge $Q$ and bed slope $s$ were involved to test different formative conditions and experimental setups (see Table 1).

Table 1. Hydraulic conditions and dimensionless parameters involved in the experiments with alternate bars: $s$ is the bed slope, $Q$ the flow discharge, $\mathrm{D}_{0}$ and $U_{0}$ the depth and the flow velocity of the reference flow, respectively, $F r$ the Froude number, $Q s$ the sediment transport rate, $\beta$ the aspect ratio and $\beta_{c r}$ the critical aspect ratio for the formation of alternate bars.

\begin{tabular}{|c|c|c|c|c|c|c|c|c|}
\hline ID & $\begin{array}{c}\boldsymbol{s} \\
{[\mathbf{m m} / \mathbf{m}]}\end{array}$ & $\begin{array}{c}\boldsymbol{Q} \\
{[\mathbf{I} / \mathbf{s}]}\end{array}$ & $\begin{array}{c}\boldsymbol{D}_{\mathbf{0}} \\
{[\mathbf{c m}]}\end{array}$ & $\begin{array}{c}\boldsymbol{U}_{\mathbf{0}} \\
{[\mathbf{m} / \mathbf{s}]}\end{array}$ & $\begin{array}{c}\boldsymbol{F r} \\
{[-]}\end{array}$ & $\begin{array}{c}\boldsymbol{Q s} \\
{[\mathbf{g} / \mathbf{s}]}\end{array}$ & $\begin{array}{c}\boldsymbol{\beta} \\
{[-]}\end{array}$ & $\begin{array}{c}\boldsymbol{\beta}_{\boldsymbol{c r}} \\
{[-]}\end{array}$ \\
\hline 1 & 5 & 4 & 2.5 & 0.37 & 0.75 & 1.0 & 8.6 & 4.2 \\
\hline 2 & 6 & 4 & 2.4 & 0.39 & 0.81 & 2.2 & 9.1 & 5.2 \\
\hline 3 & 8 & 3 & 1.8 & 0.38 & 0.89 & 2.6 & 11.7 & 5.0 \\
\hline 4 & 8 & 4 & 2.2 & 0.43 & 0.92 & 5.2 & 9.9 & 6.0 \\
\hline 5 & 9 & 3 & 1.8 & 0.39 & 0.95 & 3.87 & 12.2 & 5.2 \\
\hline 6 & 9 & 4 & 2.1 & 0.44 & 0.97 & 7 & 10.2 & 6.1 \\
\hline
\end{tabular}


Each combination of flow discharge and bed slope was run until achieving the dynamic equilibrium of alternate bars in the channel: we defined such equilibrium when both sediment transport rate at the end of the flume was equal to the feeding rate (manually adjusted to the value obtained from Wong \& Parker relation [13]) and the wavelength of the alternate bars was constant. These conditions were satisfied within about 40 hours of running for most of the experiments. Once the equilibrium was obtained, we stopped flow and solid input, allowing water to slowly flow away. At this point, we could take pictures of the flume bed and reconstruct its morphology using Structure-from-Motion technology via PhotoScan and QGIS software [14]. Bed monitoring has been carried out also during the run of each experiment at regular intervals (4-8 hours), by temporary switching off the recirculating pump, to evaluate bed topography evolution in time (Fig. 1).

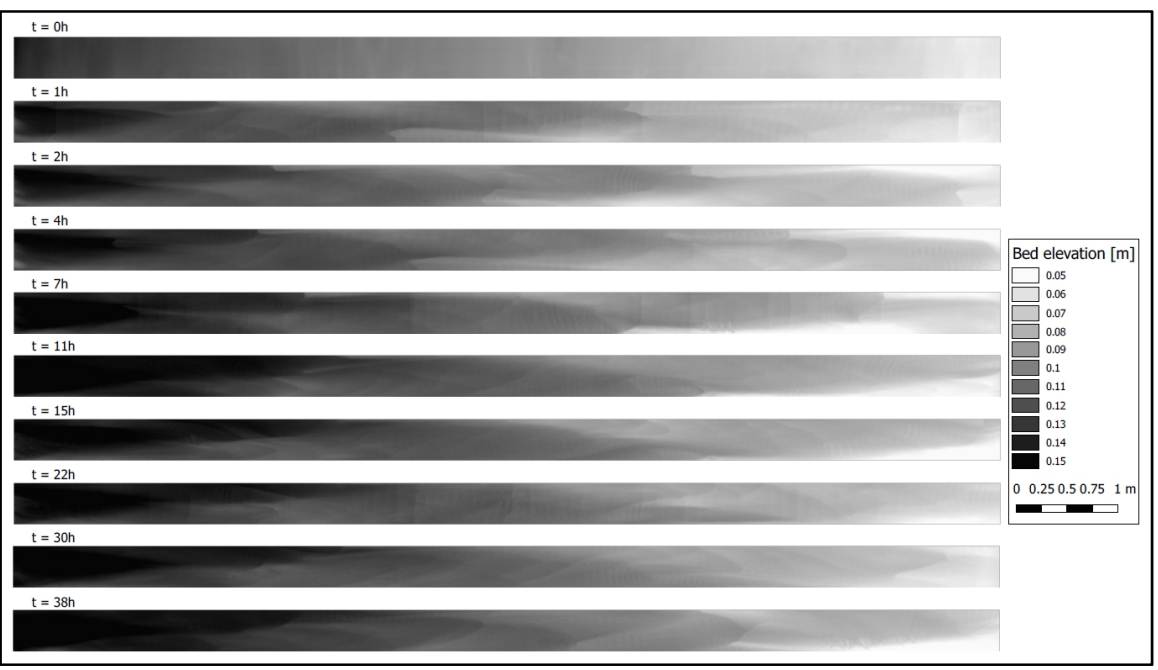

Fig. 1. DEMs at different time intervals reconstructed using Structure-from-Motion technology for the experiment $\mathrm{ID}=3$ (Table 1 ) without vegetation.

During the run of the experiments, we also measured the flow field on water surface along an entire alternate bar by means of tracers, photogrammetric survey and subsequent analysis with FUDAA-LSPIV software [15]. An example of surface flow field measured during one of the experiments is reported in Fig. 2.

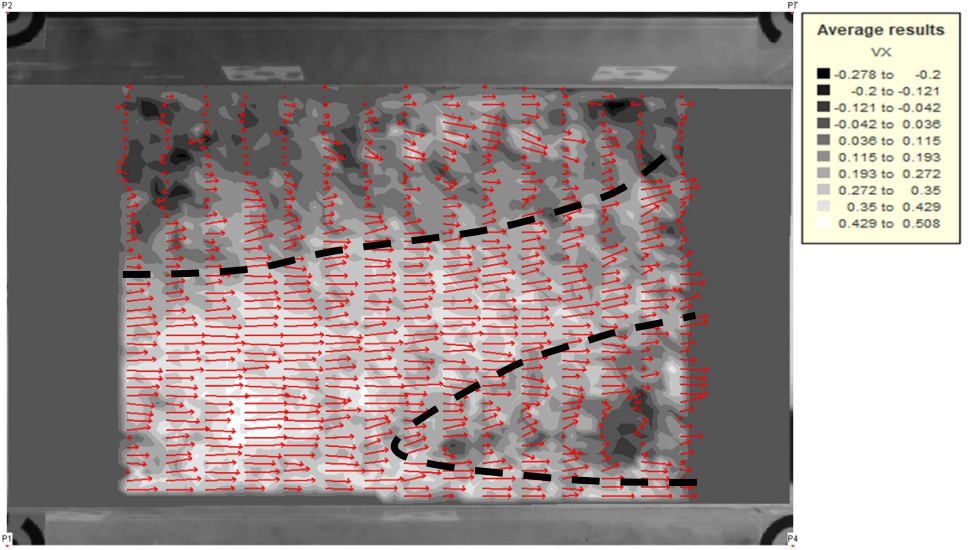

Fig. 2. Surface flow field highlighted by red arrows at the downstream part of a bar. Bar edges are identified by black dashed lines. Flow is from left to right. 
Once the dynamic equilibrium was achieved and bed topography measured, we installed rigid cylinders on the most elevated areas of the already formed alternate bars to simulate the presence and effects of mature vegetation (i.e., trees). As a matter of fact, this type of vegetation has been found to control the long-term evolution of a river reach $[4,6,8]$ and rigid cylinders appears to be suitable to mimic such plants [7, 8]. These experiments simulate sediment bars where mature vegetation was able to fully grow as a consequence of the lack of floods able to uproot the younger vegetation. Importantly, vegetation was placed on the bars accordingly to field observations made by Hortobagyi et al. [16] regarding its distribution, diameter and density: particularly, we used $1 \mathrm{~mm}$ diameter metallic rod, $2 \mathrm{~cm}$ longitudinally and transversally spaced. After installing the vegetation, hydraulic pump was then switched on again to continue running the experiments.

\section{Preliminary results}

With regard to experiment $\mathrm{ID}=3$ that we carried out with bed slope of $0.8 \%$ and flow discharge of $3 \mathrm{l} / \mathrm{s}$, we observed an initial tendency to aggradation, mostly related to the slightly lower sediment transport rate observed in the flume compared to the feeding rate.

Table 2. Bar length $(L)$, amplitude $(H)$ and celerity $(c)$ for the experiment $I D=3$ without vegetation. Subscript CST refers to the values predicted by theory of Colombini et al. [10].

\begin{tabular}{|c|c|c|c|c|c|}
\hline $\begin{array}{c}\boldsymbol{L}_{\text {CST }} \\
{[\mathbf{m}]}\end{array}$ & $\begin{array}{c}\boldsymbol{L} \\
{[\mathbf{m}]}\end{array}$ & $\begin{array}{c}\boldsymbol{H}_{\text {CST }} \\
{[\mathbf{c m}]}\end{array}$ & $\begin{array}{c}\boldsymbol{H} \\
{[\mathbf{c m}]}\end{array}$ & $\begin{array}{c}\boldsymbol{c}_{\text {CST }} \\
{[-]}\end{array}$ & $\begin{array}{c}\boldsymbol{c} \\
{[-]}\end{array}$ \\
\hline 1.68 & 2.66 & 3.8 & 3.0 & $5 \cdot 10^{-5}$ & $2.3 \cdot 10^{-5}$ \\
\hline
\end{tabular}

The adaptation in bed slope, together with boundary conditions imposed in the laboratory flume, modified dimensions of alternate bars, particularly reducing wavelength with respect to the value predicted by theory of Colombini et al. [12], creating longer and slower bars. Results for this experiment are presented in Table 2.

We measured the average migration rate as the length covered by bar front between two consecutive DEMs divided by the elapsed time. Dimensionless celerity $c$ was then obtained by combining migration rate, channel width $W$ and reference flow velocity $U_{0}$. For the sake of clarity, bar length $L$ and celerity $c$ are the average values among all different DEMs.
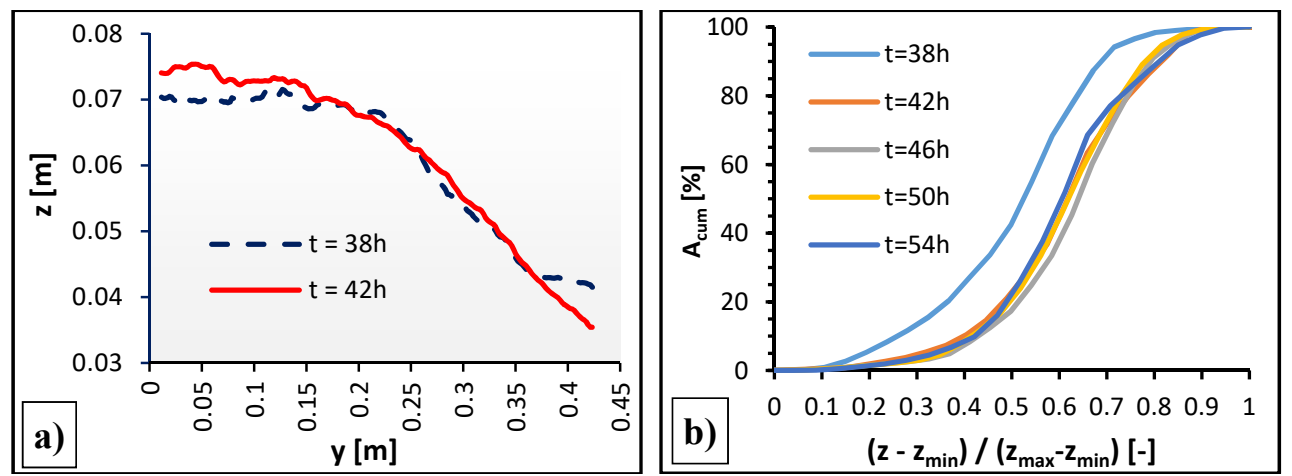

Fig. 3. Results and comparison for the experiment $I D=3$ without and with vegetation. a) Transversal bed profile elevations for the same cross section $(x=9.8 \mathrm{~m})$ at different times (dashed blue line at $\mathrm{t}=38 \mathrm{~h}$ without vegetation, continuous red line 4 hours later that vegetation was installed. $\mathrm{b}$ ) Bed area distribution along the whole flume with respect to dimensionless bed elevation for different times after placing vegetation. Line at $\mathrm{t}=38 \mathrm{~h}$ is given as comparison for the same setup without vegetation. ). 
For the same conditions of flow discharge and bed slope, we carried out a comparison among experiments before and after placing the vegetation. The comparison is focused on both wavelength and amplitude of alternate bars as well as their downstream migration rate. The comparison between bare and vegetated bars shows an increase in the wave height with deeper pools and higher deposit (Fig. 3a). Similar results were obtained by Rominger et al. [11] in their experiments with forced bars in a meandering channel. Figure $3 b$ illustrates the effect of vegetation on the overall topographic pattern; it appears that vegetation favours sediment deposition as the average bed elevation increases, moreover it produces a remarkable expansion of the areas located above the average bed elevation. A comparison of the DEMs before and after vegetation placement (Fig. 4) shows the formation of a deposit downstream the vegetation patches, which contributes to make bars even longer.

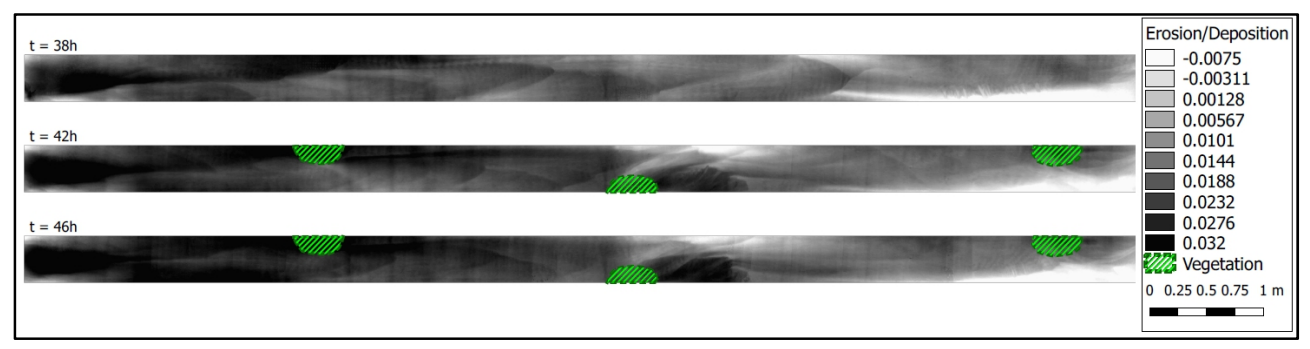

Fig. 4. DEMs at different time intervals reconstructed using Structure-from-Motion technology for the experiment $\mathrm{ID}=3$ (Table 1 ) after vegetation placement at $\mathrm{t}=38 \mathrm{~h}$. Vegetated areas area dashed in green. Erosion and deposition depth refer to initial flat bed elevation. The comparison highlights deeper erosion and higher deposition patterns in vegetated bars.

The formation of this deposit happened quite fast $(+71 \%(12 \mathrm{~mm})$ between $\mathrm{t}=38 \mathrm{~h}$ and $42 \mathrm{~h})$, whereas it remained almost stable in position and height during the remaining time $(+11 \%$ between $\mathrm{t}=42 \mathrm{~h}$ and $46 \mathrm{~h})$. Importantly, the presence of vegetated patches and their downstream deposit contributed also to slow down the migration rate of bars. Particularly in this case, we didn't observe any further downstream bar migration.

\section{Conclusions and future developments}

In this paper we present preliminary results of our work focused on the dynamics of vegetated alternate bar patterns.

Our preliminary observations highlight that the presence of vegetation acts as a forcing term for bar evolution. As in the case of forced bars induced by, for instance, channel curvature, the evolution of vegetated bars follows the dynamics of the forcing action. In our case, the presence of rigid stems positioned on the highest areas of bar deposit, representing patches of hardwood riparian forest, halts the bar migration and increases the amplitude of bed deformations. Moreover, plants increase the planimetric extension of bar deposit thus providing a positive feedback for colonization and establishment of pioneer vegetation.

Future developments will include the investigation of the whole set of configurations for bar formation and a detailed analysis of bar morphology and dynamics according to different vegetation density, spatial distribution and arrangements.

The authors thanks two anonymous reviewers for their helpful comments and useful suggestions. 


\section{References}

1. D. Corenblit, E. Tabacchi, J. Steiger, A. M. Gurnell. Reciprocal interactions and adjustments between fluvial landforms and vegetation dynamics in river corridors: a review of complementary approaches. Earth-Science Reviews 84 (1): 56-86 (2007)

2. A. B. Murray, C. Paola. Modelling the effect of vegetation on channel pattern in bedload rivers. Earth Surface Processes and Landforms 28 (2): 131-143 (2003)

3. T.J. Coulthard, D. M. Hicks, M. J. Van de Wiel. Cellular modelling of river catchments and reaches: advantages, limitations and prospects. Geomorphology 90 (3): 192-207, (2007)

4. A. Crosato, M. S. Saleh. Numerical study on the effects of floodplain vegetation on river planform style. Earth Surface Processes and Landforms 36 (6): 711-720 (2011)

5. W. Bertoldi, A. Siviglia, S. Tettamanti, M. Toffolon, D. Vetsch, S. Francalanci. Modeling vegetation controls on fluvial morphological trajectories. Geophysical Research Letters 41 (20): 7167-7175 (014)

6. M. Van Oorschot, M. G. Kleinhans, G. Geerling, H. Middelkoop Distinct patterns of interaction between vegetation and morphodynamics. Earth Surface Processes and Landforms (2015)

7. A. Vargas-Luna, A. Crosato, G. Calvani, W. S. J. Uijttewaal. Representing plants as rigid cylinders in experiments and models. Advances in Water Resources (2015)

8. L. Solari, M. Van Oorschot, B. Belletti, D. Hendriks, M. Rinaldi, A. Vargas-Luna. Advances on modelling riparian vegetation-hydromorphology interactions. River Research and Applications (2015)

9. S. J. Bennett, T. Pirim, B. D. Barkdoll. Using simulated emergent vegetation to alter stream flow direction within a straight experimental channel. Geomorphology, 44 (2002).

10. M. Tal, C. Paola. Effects of vegetation on channel morphodynamics: results and insights from laboratory experiments. Earth Surface Processes and Landforms 35 (9): 1014-1028 (2010)

11. J. T. Rominger, A. F. Lightbody, H. M. Nepf, H. M. Effects of added vegetation on sand bar stability and stream hydrodynamics. Journal of Hydraulic Engineering, 136(12), 994-1002 (2010)

12. M. Colombini, G. Seminara, M. Tubino. Finite-amplitude alternate bars. Journal of Fluid Mechanics, 181, 213-232 (1987)

13. M. Wong, G. Parker. Reanalysis and correction of bed-load relation of Meyer-Peter and Müller using their own database. Journal of Hydraulic Engineering, 132(11), 11591168 (2006)

14. J. A. Morgan, D. J. Brogan, P. A. Nelson. Application of Structure-from-Motion photogrammetry in laboratory flumes. Geomorphology 276 (2017)

15. J. Le Coz, A. Hauet, G. Pierrefeu, G. Dramais, B. Camenen. Performance of imagebased velocimetry (LSPIV) applied to flash-flood discharge measurements in Mediterranean rivers. Journal of Hydrology, 394(1-2), 42-52 (2010)

16. B. Hortobágyi, D. Corenblit, J. Steiger, J. L. Peiry. Niche construction within riparian corridors. Part I: Exploring biogeomorphic feedback windows of three pioneer riparian species (Allier River, France). Geomorphology (2017) 